\title{
Braden scale for assessing pneumonia after acute ischaemic stroke
}

Yunlong Ding ${ }^{1+}$, Yazhou Yan ${ }^{2+}$, Jiali Niu ${ }^{3+}$, Yanrong Zhang ${ }^{1 \dagger}$, Zhiqun Gu', Ping Tang ${ }^{1 *}$ and Yan Liu ${ }^{1 *}$ (D)

\begin{abstract}
Background: The prevention of pneumonia is critical for patients with acute ischaemic stroke (AIS). The six subscales in the Braden Scale seem to be related to the occurrence of pneumonia. We aimed to evaluate the feasibility of using the Braden Scale to predict the occurrence of pneumonia after AIS.

Methods: We studied a series of consecutive patients with AlS who were admitted to the hospital. The cohort was subdivided into pneumonia and no pneumonia groups. The scores on the Braden Scale, demographic characteristics and clinical characteristics were obtained and analysed by statistical comparisons between the two groups. We investigated the predictive validity of the Braden Scale by receiver operating characteristic (ROC) curve analysis.

Results: A total of 414 patients with AIS were included in this study. Of those 414 patients, 57 (13.8\%) patients fulfilled the criteria for post-stroke pneumonia. There were significant differences in age and histories of chronic obstructive pulmonary disease (COPD), dysphagia and Glasgow Coma Scale (GCS) score between the two groups, and the National Institutes of Health Stroke Scale (NIHSS) score in the pneumonia group was significantly higher than that in the no pneumonia group $(P<0.01)$. The mean score on the Braden Scale in the pneumonia group was significantly lower than that in the no pneumonia group $(P<0.01)$. The six subscale scores on the Braden Scale were all significantly different between the two groups. The area under the curve (AUC) for the Braden Scale for the prediction of pneumonia after AlS was $0.883(95 \% \mathrm{Cl}=0.828-0.937)$. With 18 points as the cutoff point, the sensitivity was $83.2 \%$, and the specificity was $84.2 \%$.
\end{abstract}

Conclusion: The Braden Scale with 18 points as the cutoff point is likely a valid clinical grading scale for predicting pneumonia after AlS at presentation. Further studies on the association of the Braden Scale score with stroke outcomes are needed.

Keywords: The Braden scale, Acute ischaemic stroke, Pneumonia

\section{Background}

Currently, ischaemic stroke is one of the most important causes of death and disability in China, which results in substantial social and economic burdens [1]. Pneumonia is a common medical complication after acute ischaemic stroke (AIS) [2, 3], resulting in a longer length of hospital stay and higher risks of mortality and morbidity [4]. Effective prevention is more critical than the treatment of pneumonia. Factors that have been associated with

\footnotetext{
* Correspondence: tangping12345678@sina.com; liuyan151617@163.com †Yunlong Ding, Yazhou Yan, Jiali Niu and Yanrong Zhang contributed equally to this work, and should be listed as co-first authors.

'Department of Neurology, Jingjiang People's Hospital, the Seventh Affiliated Hospital of Yangzhou University, No. 28, Zhongzhou Road, Jingjiang CN 214500, Jiangsu, China

Full list of author information is available at the end of the article
}

pneumonia after AIS include older age, dysarthria/aphasia, cognitive impairment, stroke severity, long-term bedridden status, dysphagia, and decreased body resistance $[5,6]$. We hope to find an effective scale to predict the risk of pneumonia in patients with AIS according to these risk factors.

The Braden Score is an important assessment method for judging the risk of pressure ulcers, and it involves six different risk factors: sensory perception, skin moisture, activity, mobility, nutrition, and friction and shear [7]. These indexes in the Braden Scale seem to be related to the occurrence of pneumonia. In this paper, we retrospectively analysed the correlation between the Braden Scale score and pneumonia after AIS in the stroke centre of our hospital, to evaluate the feasibility of using the

(c) The Author(s). 2019 Open Access This article is distributed under the terms of the Creative Commons Attribution 4.0 International License (http://creativecommons.org/licenses/by/4.0/), which permits unrestricted use, distribution, and 
Braden Scale to predict the occurrence of pneumonia after AIS.

\section{Methods \\ Study participants}

This retrospective study included AIS patients who were admitted to the stroke centre of our hospital between December 2015 and December 2018. The inclusion criteria were as follows: 1 ) aged $\geq 18$ years; 2 ) hospitalized with the primary diagnosis of AIS according to the World Health Organization criteria [8]; and 3) AIS confirmed by brain CT or MRI. The exclusion criteria were as follows: 1) transient ischaemic attack or subarachnoid haemorrhage and 2) pneumonia that occurred before admission. Pneumonia after AIS was diagnosed according to the Centers for Disease Control and Prevention criteria [9] for hospital-acquired pneumonia, on the basis of clinical and laboratory indexes of respiratory tract infection (fever, productive cough with purulent sputum, auscultatory respiratory crackles, bronchial breathing, or positive sputum culture) and supported by abnormal chest radiographic findings.

\section{Data collection}

Demographic and clinical characteristics were obtained at admission including demographic data (age and sex), associated risk factors (hypertension, hyperlipidaemia, diabetes, past stroke or transient ischaemic attack history, history of smoking and drinking, history of chronic obstructive pulmonary disease (COPD), dysphagia and the Glasgow Coma Scale (GCS) score), physical examination results (systolic blood pressure and diastolic blood pressure), laboratory examination results (total cholesterol, triglyceride, low-density lipoprotein cholesterol, high-density lipoprotein cholesterol, fasting blood glucose, glycosylated haemoglobin and serum creatinine levels), the aetiological classification of the ischaemic stroke (large atherosclerotic stroke, arteriolar occlusive stroke, cardiogenic cerebral embolism, other stroke with definite aetiology and stroke of unknown aetiology) and the National Institutes of Health Stroke Scale (NIHSS) score.

The Braden Scale is measured $24 \mathrm{~h}$ after admission by nurses and is composed of six subscales: sensory perception, skin moisture, activity, mobility, nutrition, and friction and shear. The minimum score for each item is 1 (worst), and the maximum score is 4 (best), except for the scores for friction and shear, which range from 1 to 3 . The summed scores range from 6 to 23, with lower scores associated with a higher risk [10].

\section{Statistical analysis}

Statistical comparisons were made for pneumonia versus no pneumonia after AIS. For normally distributed continuous variables (described as the mean $\pm \mathrm{SD}$ ), analysis was performed using unpaired Student's $t$ tests. For nonnormally distributed continuous variables, analysis was performed using the Mann-Whitney $U$ test. Categorical variables were analysed by the chi-square test or Fisher's exact test. Statistical analysis was performed using SPSS version 21.0 (SPSS Inc., Chicago, IL, USA). A $P$-value < 0.05 was considered statistically significant. Then, we investigated the predictive validity of the Braden Scale for pneumonia after AIS by receiver operating characteristic (ROC) curve analysis. An area under the curve (AUC) of $0.97-1.00$ indicates excellent accuracy; 0.93 to 0.96 indicates very good accuracy; and 0.75 to 0.92 indicates good accuracy. However, an AUC $<0.75$ indicates obvious deficiencies, and an AUC of 0.5 indicates that the test has no predictive ability [11].

\section{Results}

\section{Subject characteristics}

In total, 525 patients with AIS were admitted to the stroke centre of our hospital between December 2015 and December 2018. Among them, 56 patients were discharged from the hospital within 2 days, and 55 patients had incomplete or missing data. Finally, 414 patients with AIS were included in this study. A total of 57 of the 414 (13.8\%) patients fulfilled the criteria for hospitalacquired pneumonia, and 357 (86.2\%) had no pneumonia. The study population had a mean age of 71.5 years, ranging from 50 to 89 years. Almost $63.8 \%$ of the patients (264) were men, and $36.2 \%$ of the patients (150) were women.

\section{Correlations of demographic and clinical characteristics between two groups}

The demographic data (sex), associated vascular risk factors (hypertension, hyperlipidaemia, diabetes, past stroke or transient ischaemic attack history, history of smoking and drinking), physical examination (systolic blood pressure, diastolic blood pressure), laboratory examination (total cholesterol, triglyceride, low-density lipoprotein cholesterol, high-density lipoprotein cholesterol, fasting blood glucose, glycosylated haemoglobin, and serum creatinine levels) had no significant differences between the pneumonia and no pneumonia groups. There were significant differences in age, history of COPD, dysphagia and GCS score between the two groups. A significant difference also emerged between the two groups in the NIHSS score, which was significantly higher in the pneumonia group than in the no pneumonia group $(13.6 \pm 5.0$ vs $9.2 \pm 3.6, \quad P<0.01)$. (Table 1).

The mean score on the Braden Scale in the pneumonia group was $15.263 \pm 2.579$, which was significantly lower than that in the no pneumonia group $(19.546 \pm 2.265, P<$ 0.05). (Table 1) The six subscale scores on the Braden Scale 
Table 1 Demographic and clinical characteristics of the two groups

\begin{tabular}{|c|c|c|c|}
\hline Items & No pneumonia $(n=357)$ & $\begin{array}{l}\text { Pneumonia } \\
(n=57)\end{array}$ & $P$ value \\
\hline Age/year & $71.0 \pm 8.9$ & $74.7 \pm 7.5$ & 0.001 \\
\hline Male (case, \%) & $225(63.0)$ & $39(68.4)$ & 0.462 \\
\hline Smoking status (case, \%) & $140(39.2)$ & $28(49.1)$ & 0.191 \\
\hline Drinking status (case, \%) & $147(27.4)$ & $22(38.6)$ & 0.773 \\
\hline Hypertension (case, \%) & $195(54.6)$ & $34(59.6)$ & 0.642 \\
\hline Hyperlipidemia (case, \%) & $101(28.3)$ & $12(21.1)$ & 0.336 \\
\hline Diabetes (case, \%) & $96(26.9)$ & $18(31.6)$ & 0.523 \\
\hline Stroke/TIA (case, \%) & $36(10.1)$ & $5(8.8)$ & 1.000 \\
\hline COPD (case, \%) & $6(1.7)$ & $4(7.0)$ & 0.036 \\
\hline Dysphagia (case, \%) & $54(15.1)$ & 18 (31.6) & 0.004 \\
\hline Admission GCS score & $14.0 \pm 2.2$ & $10.9 \pm 4.3$ & 0.000 \\
\hline Fasting blood glucose (mmol/L) & $5.9 \pm 1.6$ & $5.8 \pm 0.76$ & 0.255 \\
\hline Glycosylated hemoglobin (\%) & $5.8 \pm 0.7$ & $5.8 \pm 0.7$ & 0.822 \\
\hline Serum creatinine (umol/L) & $80.4 \pm 20.6$ & $82.0 \pm 25.1$ & 0.595 \\
\hline Systolic blood pressure (mmHg) & $145.5 \pm 17.7$ & $143.1 \pm 17.4$ & 0.342 \\
\hline Diastolic blood pressure $(\mathrm{mmHg})$ & $87.3 \pm 10.9$ & $89.4 \pm 10.0$ & 0.189 \\
\hline Total cholesterol (mmol/L) & $5.0 \pm 1.2$ & $5.2 \pm 1.6$ & 0.329 \\
\hline Triglyceride (mmol/L) & $1.5 \pm 0.8$ & $1.4 \pm 0.5$ & 0.594 \\
\hline Low density lipoprotein cholesterol (mmol/L) & $3.1 \pm 0.8$ & $3.1 \pm 0.8$ & 0.955 \\
\hline High density lipoprotein cholesterol (mmol/L) & $1.2 \pm 0.5$ & $1.2 \pm 0.4$ & 0.571 \\
\hline \multicolumn{4}{|l|}{ Stroke classification } \\
\hline Large atherosclerotic stroke(case, \%) & $140(39.2)$ & $26(45.6)$ & 0.384 \\
\hline Arteriolar occlusive stroke(case, \%) & $90(25.2)$ & $19(33.3)$ & 0.199 \\
\hline Cardiogenic cerebral embolism(case, \%) & $49(13.7)$ & $3(5.3)$ & 0.085 \\
\hline Other stroke with definite etiology(case, \%) & $34(10.0)$ & $3(5.3)$ & 0.452 \\
\hline Stroke of unknown etiology(case, \%) & $44(12.3)$ & $6(10.5)$ & 0.829 \\
\hline Admission NIHSS score & $9.2 \pm 3.6$ & $13.6 \pm 5.0$ & 0.000 \\
\hline Braden scale at $24 \mathrm{~h}$ & $19.6 \pm 2.3$ & $15.3 \pm 2.5$ & 0.000 \\
\hline
\end{tabular}

The NIHSS score in the pneumonia group was significantly higher than that in the no pneumonia group. The mean score on the Braden Scale in the pneumonia group was significantly lower than that in the no pneumonia group

TIA transient ischaemic attack, COPD chronic obstructive pulmonary disease, GCS Glasgow Coma Scale, NIHSS National Institutes of Health Stroke Scale

all had significant differences between the two groups.

(Table 2).

The validity of the association between the Braden scale/ NIHSS score and pneumonia after acute ischaemic stroke

The AUC for the Braden Scale for the prediction of pneumonia after acute ischaemic was $0.883(95 \% \mathrm{CI}=$ $0.828-0.937)$. Additionally, with 18 points as the cutoff point, the sensitivity was $83.2 \%$, and the specificity was $84.2 \%$. It was suggested that the incidence of pneumonia in patients with AIS can be predicted by a cutoff value of 18 points on the Braden Scale, with a sensitivity of $83.2 \%$ and a specificity of $84.2 \%$. (Fig. 1 ).

The AUC for the NIHSS score for the prediction of pneumonia after AIS was 0.767 (95\% CI $=0.697-0.837$ ).
Table 2 The Braden Scale scores in the two groups (mean \pm SD)

\begin{tabular}{llll}
\hline Braden scale & $\begin{array}{l}\text { No pneumonia } \\
(n=357)\end{array}$ & $\begin{array}{l}\text { Pneumonia } \\
(n=57)\end{array}$ & $P$ value \\
\hline Sensory perception & $3.7 \pm 0.5$ & $2.8 \pm 0.7$ & 0.000 \\
Skin moisture & $4.0 \pm 0.2$ & $3.7 \pm 0.6$ & 0.000 \\
Activity & $3.0 \pm 1.0$ & $1.6 \pm 1.0$ & 0.000 \\
Mobility & $3.5 \pm 0.6$ & $2.5 \pm 0.6$ & 0.000 \\
Nutrition & $3.0 \pm 0.3$ & $2.8 \pm 0.4$ & 0.001 \\
Friction and shear & $2.4 \pm 0.6$ & $1.9 \pm 0.5$ & 0.000 \\
Sum score & $19.6 \pm 2.3$ & $15.3 \pm 2.5$ & 0.000 \\
\hline
\end{tabular}

The scores on the six subscales of the Braden Scale were all significantly different between the two groups 


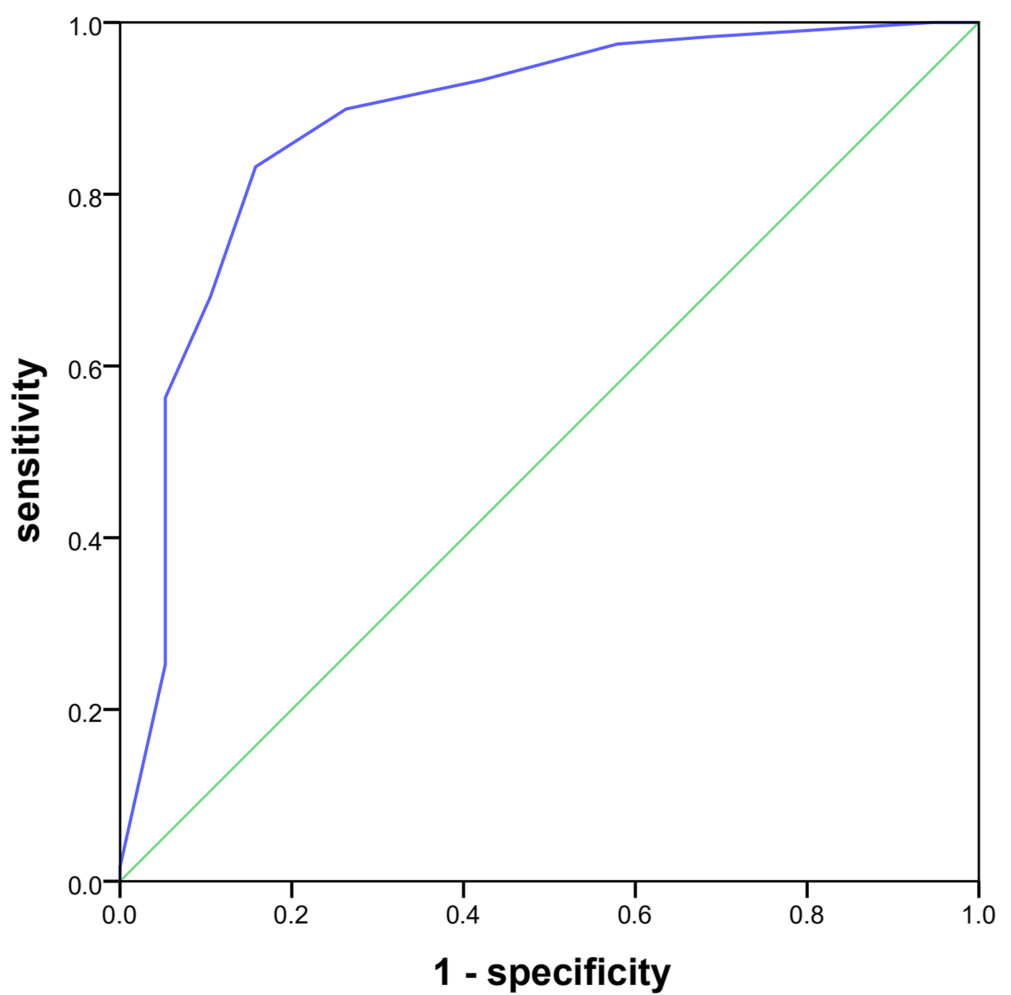

Fig. 1 ROC curve for the Braden Scale. The AUC for the Braden Scale for the prediction of pneumonia after acute ischaemic stroke was 0.883 ( $95 \% \mathrm{Cl}=0.828-0.937$ ). With 18 points as the cutoff point, the sensitivity was $83.2 \%$, and the specificity was $84.2 \%$

With 12 points as the cutoff point, the sensitivity was $73.7 \%$, and the specificity was $73.1 \%$. (Fig. 2).

\section{Discussion}

The primary objective of the present study was to find an effective and simple scale to identify patients at high risk of pneumonia after AIS. This was the first study to evaluate the feasibility of using the Braden Scale to predict the occurrence of pneumonia after AIS. Stroke is one of the leading causes of death at the national level in China [12]. Ageing is an important risk factor for stroke [13], and as life expectancy increases, the incidence of stroke also rises. Therefore, exploring the prevention and treatment of stroke and stroke complications is important for reducing the mortality rate of stroke patients.

In this study, pneumonia was found in $13.8 \%$ of patients presenting with an AIS, which was similar to the incidence in prior studies, which ranged from 5 to 26\% [14-17]. Post-stoke pneumonia is associated with reduced early and long-term survival, longer hospitalization times, and higher degrees of disability at discharge [4]. Therefore, it is very important to prevent post-stoke pneumonia. However, a systematic review on the efficacy of early antibiotic prophylaxis after stroke failed to show a benefit in patients' outcomes [18]. This might be due to the inclusion of patients with a low risk of developing post-stoke pneumonia in these studies. It is critical to find an effective scale to predict the occurrence of pneumonia in patients after AIS and to intervene in high-risk patients to prevent pneumonia and improve the outcome. The Braden Scale is composed of six subscales, namely, sensory perception, skin moisture, activity, mobility, nutrition, friction and shear, which seem to be related to the occurrence of pneumonia. One study found that the Braden Scale score can predict the prognosis of elderly people with mobility impairment [19], and our study found that the mean score on the Braden Scale in the pneumonia group was significantly lower than that in the no pneumonia group. Furthermore the scores on the six subscales of the Braden Scale were significantly different between the two groups. The AUC for the Braden Scale for the prediction of post-stoke pneumonia was 0.883 , which was identified as good accuracy, as shown above. With 18 points as the cutoff point, the sensitivity and specificity were high. Given that patients with lower Braden scores are at high risk for SAP, they should be screened in a timely fashion and receive early interventions to achieve the goal of reducing SAP. In addition, the use of the Braden Scale score allows medical staff to more accurately identify patients at high risk for developing SAP, increasing clinical care efficiency. 


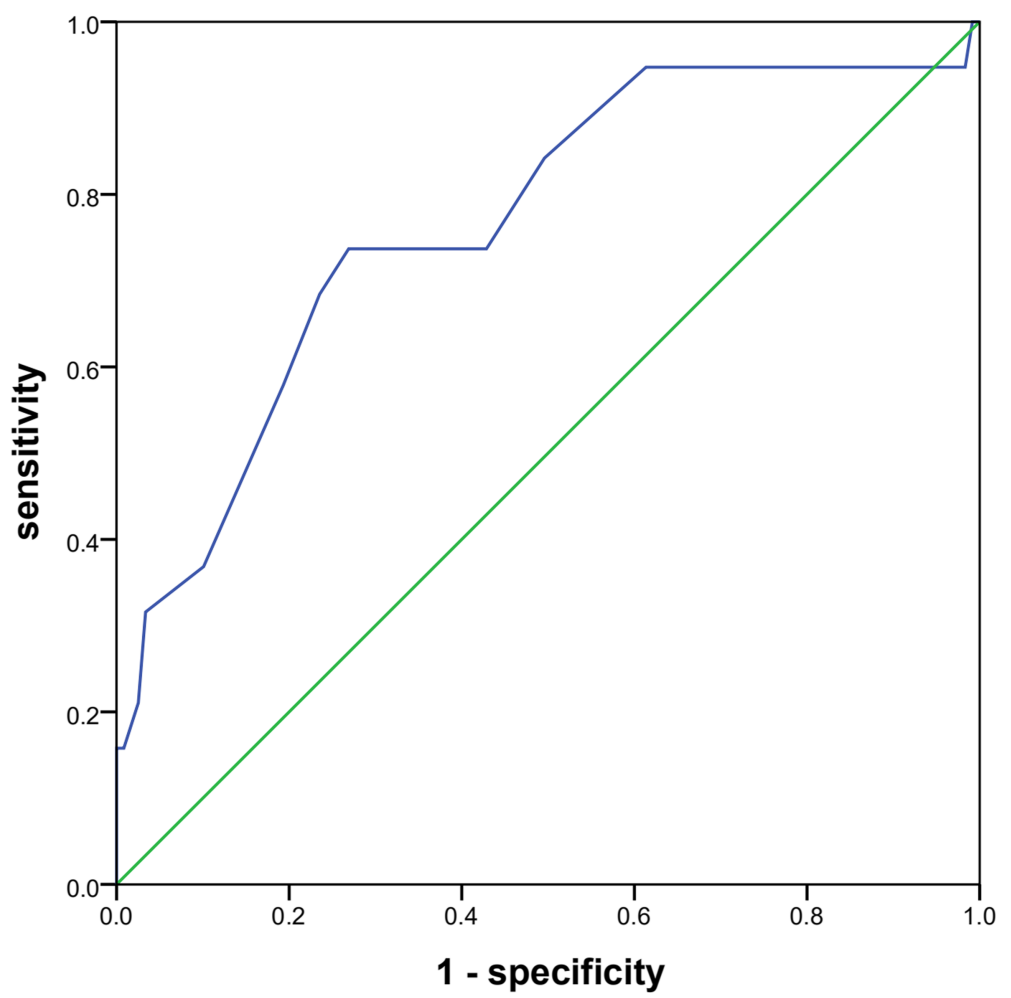

Fig. 2 ROC curve for the NIHSS score. The AUC for the NIHSS score for the prediction of pneumonia after acute ischaemic stroke was 0.767 (95\% $\mathrm{Cl}=0.697-0.837)$. With 12 points as the cutoff point, the sensitivity was $73.7 \%$, and the specificity was $73.1 \%$

Table 3 Models to predict post-stoke pneumonia

\begin{tabular}{|c|c|c|c|c|}
\hline Author, year & Study design & $\begin{array}{l}\text { No. of } \\
\text { patients }\end{array}$ & Predictors & C-statistic \\
\hline $\begin{array}{l}\text { Kwon et al., } 2006 \\
\text { [20] }\end{array}$ & $\begin{array}{l}\text { Retrospective } \\
\text { cohort }\end{array}$ & 286 & Age, sex, NIHSS, dysphagia, mechanical ventilation & NR \\
\hline $\begin{array}{l}\text { Sellars et al., } \\
2007[6]\end{array}$ & $\begin{array}{l}\text { Retrospective } \\
\text { cohort }\end{array}$ & 412 & $\begin{array}{l}\text { Age, dysarthria, abbreviated mental test score, modified Rankin Scale score, and water } \\
\text { swallowing test }\end{array}$ & 0.90 \\
\hline $\begin{array}{l}\text { Chumbler et al., } \\
2010 \text { [27] }\end{array}$ & $\begin{array}{l}\text { Retrospective } \\
\text { cohort }\end{array}$ & 925 & $\begin{array}{l}\text { Age, stroke severity, dysphagia, history of pneumonia, patient being 'found down' at } \\
\text { symptom onset }\end{array}$ & 0.78 \\
\hline $\begin{array}{l}\text { Hoffmann et al., } \\
2012 \text { [24] }\end{array}$ & Registry & 15,336 & Age, sex, stroke severity, dysphagia, atrial fibrillation & 0.84 \\
\hline Ji et al., 2013 [25] & Registry & 8820 & $\begin{array}{l}\text { Age, history of atrial fibrillation, congestive heart failure, COPD, current smoking, restroke } \\
\text { dependence, dysphagia, NIHSS, GCS, stroke subtype, blood glucose }\end{array}$ & 0.79 \\
\hline $\begin{array}{l}\text { Harms et al., } \\
2013 \text { [28] }\end{array}$ & $\mathrm{RCT}$ & 114 & Age, GCS, systolic arterial blood pressure, WBC count & 0.85 \\
\hline $\begin{array}{l}\text { Smith et al., } 2015 \\
{[26]}\end{array}$ & Registry & 11,551 & Age, sex, NIHSS, prestrike independence & 0.79 \\
\hline $\begin{array}{l}\text { Kumar et al., } \\
2017[29]\end{array}$ & $\begin{array}{l}\text { Retrospective } \\
\text { cohort }\end{array}$ & 1644 & Age, congestive heart failure, dysarthria, dysphagia & 0.82 \\
\hline $\begin{array}{l}\text { Westendorp } \\
\text { et al., } 2018 \text { [30] }\end{array}$ & $\mathrm{RCT}$ & 2538 & $\begin{array}{l}\text { Age, sex, pre-stroke disability, medical history of COPD, stroke severity, dysphagia, intracere- } \\
\text { bral haemorrhage }\end{array}$ & 0.82 \\
\hline Ding et al., 2019 & $\begin{array}{l}\text { Retrospective } \\
\text { cohort }\end{array}$ & 414 & Sensory perception, skin moisture, activity, mobility, nutrition, and friction and shear & 0.88 \\
\hline
\end{tabular}

NIHSS National Institutes of Health Stroke Scale, NR not reported, COPD chronic obstructive pulmonary disease, GCS Glasgow Coma Scale, RCT randomized controlled trial 
We also found that the NIHSS score in the pneumonia group was significantly higher than that in the no pneumonia group. Studies have shown that the NIHSS score is an independent risk factor for pneumonia after acute stroke [16, 20-22]. The occurrence of pneumonia in patients with a higher NIHSS score may be due to decreased consciousness or to position-induced gastroesophageal reflux. This result also suggested that the pneumonia group had a greater neurological deficit. Previous studies confirmed that patients with cardiogenic embolism tended to have more neurological deficits [23], and our study supported the conclusion that patients with cardiogenic embolism are more likely to develop pneumonia. However, the Braden Scale was better able to quantify the risk factors and evaluate the incidence of post-stoke pneumonia.

Several post-stoke pneumonia prediction models have been developed (see Table 3 for an overview of these models); however, these models have not been widely used in clinical practice. It is not our intention to show the superiority of the Braden Scale for the prediction of the occurrence of post-stoke pneumonia compared to the earlier scores; however, we want to point out the differences. Three of these prediction models were derived from and externally validated in large stroke registries: Hoffmann et al. [24], Ji et al. [25] and Smith et al. [26]. The other available models for predicting post-stroke pneumonia showed worse performance or over-fitting of the model because of their smaller sample sizes, and they often include too many predictors based on the event per variable rule [6, 19, 27-30].

Our study had some limitations. First, as a retrospective study, we cannot rule out the possibility that some other confounding factors may have impacted the development of post-stroke pneumonia, such as dementia $[31,32]$, the use of angiotensin-converting enzyme inhibitors or angiotensin receptor blockers [33]. Second, the time course for post-stroke pneumonia was unclear. We cannot conclude the causal relationship between longer hospital stay and pneumonia. Third, the study included only hospitalized patients with AIS, and those patients who were treated in outpatient clinics, were treated in the emergency department, or died shortly after admission were not included. Fourth, our study was from a single centre with a limited number of patients. Finally, the use of the Braden Scale for the prediction of the occurrence of post-stoke pneumonia needs to be further validated in additional populations.

\section{Conclusion}

In summary, the Braden Scale with 18 points as the cutoff point is a valid clinical grading scale for predicting pneumonia after AIS at presentation. Further studies on the association of the Braden Scale score with stroke outcomes are needed.

\section{Abbreviations}

AIS: Acute Ischaemic Stroke; AUC: Area Under the Curve; COPD: Chronic Obstructive Pulmonary Disease; GCS: Glasgow Coma Scale; NIHSS: National Institutes of Health Stroke Scale; ROC: Receiver Operating Curve;

TIA: Transient Ischaemic Attack

\section{Acknowledgements}

Not applicable.

\section{Authors' contributions}

Study concept and design: YL, PT and YLD. Data analysis: YZY, JLN, YRZ and ZQG. Data collection: YLD, YZY, JLN, YRZ, ZQG, PT and YL. Writing of the manuscript: YLD, YZY, JLN, YRZ and ZQG. Revising the manuscript: YL and PT. Final approval of the manuscript: all.

\section{Funding}

This work was funded by the Guidance Plan for Social Development of Taizhou Municipal Science and Technology (ssf20160141). The funder had no role in the study design, data collection, data analysis, data interpretation, writing of the report, decision to publish, or preparation of the manuscript.

\section{Availability of data and materials}

The datasets analysed during the current study are available from the corresponding author on reasonable request.

\section{Ethics approval and consent to participate}

The study was approved by the medical ethics committee of Jingjiang People's Hospital. Because it was a retrospective study and did not include any personal information related to the participants, the need to obtain written informed consent was waived. The treatment of each participant during hospitalization was approved by the patient or their close family member, and written informed consent form was obtained before treatment.

\section{Consent for publication \\ Not applicable.}

\section{Competing interests}

None of the authors report a competing interest.

\section{Author details}

'Department of Neurology, Jingjiang People's Hospital, the Seventh Affiliated Hospital of Yangzhou University, No. 28, Zhongzhou Road, Jingjiang CN 214500, Jiangsu, China. ${ }^{2}$ Department of Neurosurgery, Changhai Hospital affiliated to the Second Military Medical University, Shanghai, China. ${ }^{3}$ Department of Clinical Pharmacy, Jingjiang People's Hospital, the Seventh Affiliated Hospital of Yangzhou University, Jingjiang, Jiangsu, China.

Received: 1 June 2019 Accepted: 3 September 2019

Published online: 07 October 2019

\section{References}

1. Zhou M, Wang H, Zhu J, Chen W, Wang L, Liu S, Li Y, Wang L, Liu Y, Yin P, et al. Cause-specific mortality for 240 causes in China during 1990-2013: a systematic subnational analysis for the global burden of disease study. Lancet (London, England) 2016. 2013;387(10015):251-72.

2. Kumar S, Selim MH, Caplan LR. Medical complications after stroke. Lancet Neurol. 2010;9(1):105-18.

3. Westendorp WF, Nederkoorn PJ, Vermeij JD, Dijkgraaf MG, van de Beek D. Post-stroke infection: a systematic review and meta-analysis. BMC Neurol. 2011;11:110.

4. Finlayson O, Kapral M, Hall R, Asllani E, Selchen D, Saposnik G. Risk factors, inpatient care, and outcomes of pneumonia after ischemic stroke. Neurology. 2011;77(14):1338-45.

5. Hinchey JA, Shephard T, Furie K, Smith D, Wang D, Tonn S. Formal dysphagia screening protocols prevent pneumonia. Stroke. 2005;36(9):1972-6.

6. Sellars C, Bowie L, Bagg J, Sweeney MP, Miller H, Tilston J, Langhorne P, Stott DJ. Risk factors for chest infection in acute stroke: a prospective cohort study. Stroke. 2007;38(8):2284-91. 
7. Griswold LH, Griffin RL, Swain T, Kerby JD. Validity of the Braden scale in grading pressure ulcers in trauma and burn patients. J Surg Res. 2017;219: $151-7$.

8. Stroke--1989. Recommendations on stroke prevention, diagnosis, and therapy. Report of the WHO Task Force on Stroke and other Cerebrovascular Disorders. Stroke. 1989;20(10):1407-31.

9. Garner JS, Jarvis WR, Emori TG, Horan TC, Hughes JM. CDC definitions for nosocomial infections, 1988. Am J Infect Control. 1988;16(3):128-40.

10. Suttipong $C$, Sindhu S. Predicting factors of pressure ulcers in older Thai stroke patients living in urban communities. J Clin Nurs. 2012;21(3-4):372-9.

11. Swets JA. Measuring the accuracy of diagnostic systems. Science (New York, NY). 1988;240(4857):1285-93

12. Zhou M, Wang H, Zeng X, Yin P, Zhu J, Chen W, Li X, Wang L, Wang L, Liu $Y$, et al. Mortality, morbidity, and risk factors in China and its provinces, 1990-2017: a systematic analysis for the Global Burden of Disease Study 2017. Lancet. 2019.

13. Modig K, Talbäck M, Ziegler L, Ahlbom A. Temporal trends in incidence, recurrence and prevalence of stroke in an era of ageing populations, a longitudinal study of the total Swedish population. BMC Geriatr. 2019;19(1):31

14. Johnston KC, Li JY, Lyden PD, Hanson SK, Feasby TE, Adams RJ, Faught RE Ir, Haley EC Jr. Medical and neurological complications of ischemic stroke: experience from the RANTTAS trial. RANTTAS Investigators. Stroke. 1998; 29(2):447-53.

15. Vermeij FH, Scholte op Reimer WJ, de Man P, van Oostenbrugge RJ, Franke $\mathrm{CL}$, de Jong $\mathrm{G}$, de Kort PL, Dippel DW. Stroke-associated infection is an independent risk factor for poor outcome after acute ischemic stroke: data from the Netherlands Stroke Survey. Cerebrovascular diseases (Basel, Switzerland). 2009;27(5):465-71.

16. Aslanyan S, Weir CJ, Diener HC, Kaste M, Lees KR. Pneumonia and urinary tract infection after acute ischaemic stroke: a tertiary analysis of the GAIN international trial. Eur J Neurol. 2004;11(1):49-53.

17. Vargas M, Horcajada JP, Obach V, Revilla M, Cervera A, Torres F, Planas AM, Mensa J, Chamorro A. Clinical consequences of infection in patients with acute stroke: is it prime time for further antibiotic trials? Stroke. 2006;37(2): 461-5.

18. van de Beek D, Wijdicks EF, Vermeij FH, de Haan RJ, Prins JM, Spanjaard L, Dippel DW, Nederkoorn PJ. Preventive antibiotics for infections in acute stroke: a systematic review and meta-analysis. Arch Neurol. 2009;66(9):107681.

19. Valiani V, Chen Z, Lipori G, Pahor M, Sabbá C, Manini TM. Prognostic value of Braden activity subscale for mobility status in hospitalized older adults. Hosp Med. 2017;12(6):396-401.

20. Kwon HM, Jeong SW, Lee SH, Yoon BW. The pneumonia score: a simple grading scale for prediction of pneumonia after acute stroke. Am J Infect Control. 2006:34(2):64-8.

21. Hilker R, Poetter C, Findeisen N, Sobesky J, Jacobs A, Neveling M, Heiss WD. Nosocomial pneumonia after acute stroke: implications for neurological intensive care medicine. Stroke. 2003;34(4):975-81.

22. Grau AJ, Buggle F, Schnitzler P, Spiel M, Lichy C, Hacke W. Fever and infection early after ischemic stroke. J Neurol Sci. 1999;171(2):115-20

23. Berge T, Brynildsen J, Larssen HKN, Onarheim S, Jenssen GR, Ihle-Hansen H, Christophersen IE, Myrstad M, Rosjo H, Smith P, et al. Systematic screening for atrial fibrillation in a 65-year-old population with risk factors for stroke: data from the Akershus Cardiac Examination 1950 study. Europace. 2017; 20(FI_3):f299-f305.

24. Hoffmann S, Malzahn U, Harms H, Koennecke HC, Berger K, Kalic M, Walter G, Meisel A, Heuschmann PU. Development of a clinical score (A2DS2) to predict pneumonia in acute ischemic stroke. Stroke. 2012; 43(10):2617-23

25. Ji R, Shen H, Pan Y, Wang P, Liu G, Wang Y, Li H, Wang Y. Novel risk score to predict pneumonia after acute ischemic stroke. Stroke. 2013:44(5):1303-9.

26. Smith CJ, Bray BD, Hoffman A, Meisel A, Heuschmann PU, Wolfe CD, Tyrrell PJ, Rudd AG. Can a novel clinical risk score improve pneumonia prediction in acute stroke care? A UK multicenter cohort study. J Am Heart Assoc. 2015;4(1):e001307

27. Chumbler NR, Williams LS, Wells CK, Lo AC, Nadeau S, Peixoto AJ, Gorman M, Boice JL, Concato J, Bravata DM. Derivation and validation of a clinical system for predicting pneumonia in acute stroke. Neuroepidemiology. 2010; 34(4):193-9.

28. Harms $H$, Grittner U, Droge $H$, Meisel A. Predicting post-stroke pneumonia: the PANTHERIS score. Acta Neurol Scand. 2013;128(3):178-84.
29. Kumar S, Marchina S, Massaro J, Feng W, Lahoti S, Selim M, Herzig SJ. ACDD(4) score: a simple tool for assessing risk of pneumonia after stroke. J Neurol Sci. 2017;372:399-402.

30. Westendorp WF, Vermeij JD, Hilkens NA, Brouwer MC, Algra A, van der Worp HB, Dippel DW, van de Beek D, Nederkoorn PJ. Development and internal validation of a prediction rule for post-stroke infection and poststroke pneumonia in acute stroke patients. European Stroke J. 2018;3(2): 136-44.

31. Chen JH, Lamberg JL, Chen YC, Kiely DK, Page JH, Person CJ, Mitchell SL. Occurrence and treatment of suspected pneumonia in long-term care residents dying with advanced dementia. J Am Geriatr Soc. 2006;54(2):290-5.

32. Tinker RJ, Smith CJ, Heal C, Bettencourt-Silva JH, Metcalf AK, Potter JF, Myint PK. Predictors of mortality and disability in stroke-associated pneumonia. Acta Neurol Belg. 2019.

33. Caldeira D, Alarcao J, Vaz-Carneiro A, Costa J. Risk of pneumonia associated with use of angiotensin converting enzyme inhibitors and angiotensin receptor blockers: systematic review and meta-analysis. BMJ (Clinical research ed). 2012;345:e4260.

\section{Publisher's Note}

Springer Nature remains neutral with regard to jurisdictional claims in published maps and institutional affiliations.
Ready to submit your research? Choose BMC and benefit from:

- fast, convenient online submission

- thorough peer review by experienced researchers in your field

- rapid publication on acceptance

- support for research data, including large and complex data types

- gold Open Access which fosters wider collaboration and increased citations

- maximum visibility for your research: over $100 \mathrm{M}$ website views per year

At $\mathrm{BMC}$, research is always in progress.

Learn more biomedcentral.com/submissions 